\title{
Influence of Western North Pacific Tropical Cyclones on Their Large-Scale Environment
}

\author{
AdAm H. SOBEL \\ Department of Applied Physics and Applied Mathematics, and Department of Earth and Environmental Sciences, \\ Columbia University, New York, New York \\ SuZANA J. CAMARGo \\ International Research Institute for Climate Prediction, The Earth Institute of Columbia University, Palisades, New York
}

(Manuscript received 29 June 2004, in final form 14 January 2005)

\begin{abstract}
The authors investigate the influence of western North Pacific (WNP) tropical cyclones (TCs) on their large-scale environment by lag regressing various large-scale climate variables [atmospheric temperature, winds, relative vorticity, outgoing longwave radiation (OLR), column water vapor, and sea surface temperature (SST)] on an index of TC activity [accumulated cyclone energy (ACE)] on a weekly time scale. At all leads and lags out to several months, persistent, slowly evolving signals indicative of the El NiñoSouthern Oscillation (ENSO) phenomenon are seen in all the variables, reflecting the known seasonal relationship of TCs in the WNP to ENSO. Superimposed on this are more rapidly evolving signals, at leads and lags of one or two weeks, directly associated with the TCs themselves. These include anomalies of positive low-level vorticity, negative OLR, and high column water vapor associated with anomalously positive ACE, found in the region where TCs most commonly form and develop. In the same region, lagging ACE by a week or two and so presumably reflecting the influence of TCs on the local environment, signals are found that might be expected to negatively influence the environment for later cyclogenesis. These signals include an SST reduction in the primary region of TC activity, and a reduction in column water vapor and increase in OLR that may or may not be a result of the SST reduction.

On the same short time scale, an increase in equatorial SST near and east of the date line is seen, presumably associated with equatorial surface westerly anomalies that are also found. This, combined with the correlation between ACE and ENSO indices on the seasonal time scale, suggests the possibility that TCs may play an active role in ENSO dynamics.
\end{abstract}

\section{Introduction}

In this study, we use simple statistical methods to investigate the ways in which tropical cyclones in the western North Pacific (WNP) influence their largerscale environment. Our goal is to increase our understanding of the roles of tropical cyclones (TCs) in determining both the climatology and interannual variability of the ocean and atmosphere in the WNP region.

The influence of the large-scale environment on tropical cyclone formation and intensity has been much

Corresponding author address: Dr. Adam H. Sobel, Dept. of Applied Physics and Applied Mathematics, Columbia University, 500 West 120th Street, Room 217, New York, NY 10027.

E-mail: ahs129@columbia.edu studied, starting at least as long ago as the 1960s and 1970s (e.g., Gray 1979). Relatively little is known about the influence of tropical cyclones on the mean climate, though some arguments suggest it could be large (e.g., Emanuel 2001).

Regarding the variability, we are particularly interested in the possibility that TCs may play an active role in the dynamics of the El Niño-Southern Oscillation (ENSO). It is well known that surface westerlies on the equator are an essential part of the development of El Niño events. It is also well known that particularly strong westerly wind bursts are sometimes connected with the occurrence of twin tropical cyclones, one on each side of the equator (e.g., Keen 1982; Lander 1990; Harrison and Giese 1991; Ferreira et al. 1996). Such events are fairly rare, but several other studies have 
pointed out that, perhaps unsurprisingly, a single TC can also generate significant equatorial westerlies (Harrison and Giese 1991; Kindle and Phoebus 1995). Gao et al. (1988) argued specifically that TCs can initiate ENSO events. Without quite supporting this claim, we do present some evidence here that is consistent with the hypothesis that TCs play an active role in ENSO dynamics, by helping a warm event that is already taking place to persist or strengthen. This is discussed further in section $4 b$.

Our approach in this study is to extract the statistical signal of TCs by regressing large-scale climate variables on a weekly index of total tropical cyclone activity, the accumulated cyclone energy (ACE) in the WNP. Changes occurring over the few weeks around lag zero (the time of maximum ACE) are taken to represent the signals of the TCs and their influence on the environment. This approach-make an index, regress various fields on it-is a nonstandard approach to studying TCs on this time scale, though it is a common approach to studying other phenomena in the climate system. Typically TCs are viewed as highly episodic, isolated events, better suited to case study or composite approaches. If our goal is to understand the effects of TCs on the broader climate system at the basin scale, though, it seems to us appropriate to extract their signal using the same methods as one would use for any other climate variable, at least as a complement to other approaches.

In section 2 the data and methods are described. Section 3 describes the results. Further discussion and interpretation is given in section 4 , and conclusions are in section 5 .

\section{Data and methods}

The index used to represent tropical cyclone activity in this study is accumulated cyclone energy (Bell et al. 2000). ACE is defined as the sum of the squares of the estimated 6-hourly maximum sustained surface wind speeds (originally, in $\mathrm{knots}^{2}$; we use $\mathrm{m}^{2} \mathrm{~s}^{-2}$ ) for all tropical cyclones in the western North Pacific basin having tropical storm intensity or greater, summed over all 6-h periods in a given larger averaging period. Maximum wind speeds are obtained from the best track dataset from the Joint Typhoon Warning Center (JTWC) in the period 1950-2002 (JTWC 2004). Our sample of storms includes all of those in the JTWC dataset. Most of these occur between $100^{\circ}$ and $180^{\circ} \mathrm{E}$, but a very small number (about $1 \%$ of the 6-hourly data points) east of $180^{\circ} \mathrm{E}$ or west of $100^{\circ} \mathrm{E}$ are included, for those storms that cross those boundaries into or out of the western Pacific during their lifetimes. Figure 1 shows the climatological ACE per year per $2^{\circ} \times 2^{\circ}$ box computed from the whole dataset.

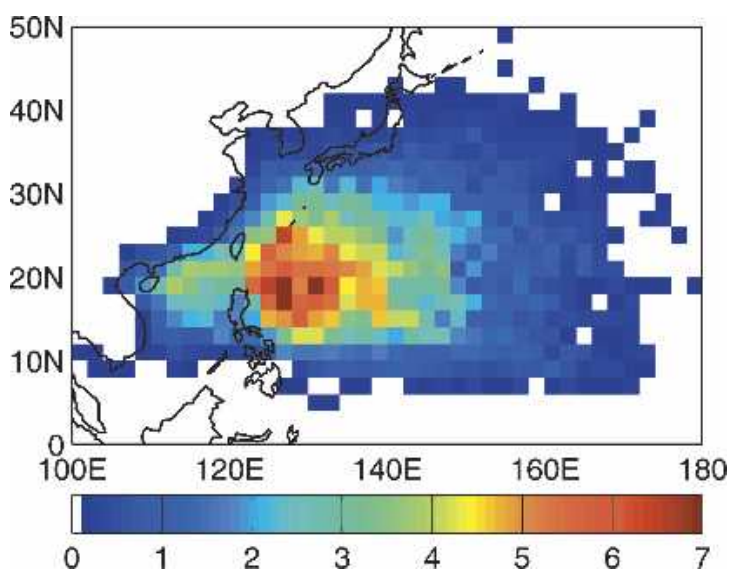

FIG. 1. Mean ACE per year in the period 1950-2002 (in $10^{3} \mathrm{~m}^{-2} \mathrm{~s}^{-2}$ ) per $2^{\circ}$ latitude/longitude.

We average over one-week periods to produce a weekly ACE time series. A weekly climatology of the annual cycle is then defined by averaging all the years over the whole record for each week and smoothing with a three-week running mean. A monthly climatology, which has essentially the same information as the weekly one used here, is shown in Camargo and Sobel (2004). The weekly climatology is subtracted from the original ACE time series to create an anomalous ACE time series. No smoothing is applied to the ACE time series before subtracting the climatology from it, so the anomalous ACE time series is unsmoothed.

ACE is not entirely ideal for our purposes. Since we are interested in the effects of TCs on the environment, an index for area-integrated storm intensity-that is, including some measure of storm size as well as intensity—would be preferable. However, a comprehensive and reliable dataset for storm size is not, to our knowledge, available.

To characterize the large-scale environment, we use several standard datasets: weekly Reynolds SST, available from November 1981 (Reynolds et al. 2002), daily National Oceanic and Atmospheric Administration (NOAA) outgoing longwave radiation (OLR) averaged weekly, available continuously since 1979 (Liebmann and Smith 1996), and several meteorological variables from the NCEP-NCAR 40-yr reanalysis (Kalnay et al. 1996), available from 1950. Each regression is computed over the whole period during which both datasets are available. To avoid any spurious influence from long-term trends, anomalies for all datasets are calculated relative to the 1971-2000 climatology, except for OLR, which is not possible, since that record begins in 1979. For the purpose of regressing OLR against ACE only, anomalies in ACE are recom- 
puted with respect to the 1979-2000 ACE climatology, to be consistent with the OLR anomalies.

$\mathrm{ACE}$ has an integral time scale (the time integral of the autocorrelation of ACE computed every $6 \mathrm{~h}$ ) of less than one week, so weekly samples can be considered independent. When lag correlating with other variables, the effective number of degrees of freedom for determining significance can be estimated using the formula of Livezey and Chen (1983). When the two time series have very different integral time scales, such as in the case of SST, which has much longer memory than ACE, the effective number of degrees of freedom given by this formula reduces to that of the time series with the shorter integral time scale. Thus we compute significance in all results below using the sample size of the ACE time series. In all plots, only results significant at the $95 \%$ confidence level according to a two-sided test are shown.

As a check on our significance estimates, we did an additional test using one field, the SST. We performed 100 regressions of SST versus ACE using an ACE time series in which the order of the years was reordered randomly in time, but the order of the time series was kept unchanged within each year. We then took the results of the original regression (using the original ACE, without reordering) to be significant at the $95 \%$ level if the correlation coefficient at a given spatial point exceeded that found in 95 of 100 randomly reordered calculations at the same point. The significance threshold thus obtained was slightly stricter than that obtained from our original test, so that a small fraction of the grid points shown as significant (in Fig. 5) were not significant by the new test (not shown). However, all the essential features discussed below remained significant. Based on this test, we consider our standard test to be adequate and use that in the figures below.

\section{Results}

In section $3 \mathrm{a}$, we show lag regressions of various quantities against $\mathrm{ACE}$ for each week from week -2 to +2 , where positive lag means that ACE leads the other fields and lag 0 is the simultaneous correlation, and the amplitudes shown represent those associated with an ACE anomaly of +1 standard deviation. Signals found during this period indicate the immediate effects of a period of anomalous TC activity on the large-scale environment. In many of the fields, weaker, but still statistically significant signals are found at longer leads and lags. These longer time scale signals are associated mainly with ENSO, and to some extent the MaddenJulian oscillation (MJO; Madden and Julian 1994), and presumably do not, for the most part, represent direct consequences of the TCs themselves. They appear in the regressions because ACE is correlated with both ENSO and the MJO. This does not necessarily mean that the TCs are entirely passive in producing these signals, as it is possible that the TCs play active roles in the dynamics of the MJO or ENSO. A sampling of these long lead-lag signals is presented in section $3 \mathrm{~b}$.

\section{a. Signals on the TC time scale}

\section{1) Vorticity}

Figure 2 shows lag regression of 850 -hPa relative vorticity on ACE. At week -2, we see an extended longitudinal band of positive vorticity, with the maximum values showing a slight $\mathrm{NW}-\mathrm{SE}$ orientation. A weaker band of negative vorticity (anticyclonic in the Northern Hemisphere) exists to the south of the positive vorticity band, centered more or less on the equator, and another one exists to the north of the positive vorticity band, forming a vaguely tripolar structure in latitude. At week 0 , the maximum positive values have become larger and concentrated further to the NW with a maximum around $20^{\circ} \mathrm{N}, 130^{\circ} \mathrm{E}$. The band of negative vorticity has also intensified and, in its western portion, shifted northward. By week +2 , the amplitude of these signals has reduced significantly, with the significant positive vorticity almost gone from the region of its maximum on week 0 . Weaker remnants of the negative vorticity remain around the Philippines, and positive vorticity in a band centered around $10^{\circ} \mathrm{N}$ and extending eastward from $150^{\circ} \mathrm{E}$.

The dominant positive vorticity signal in this figure is what could be expected from an average over a statistical distribution of tropical cyclones forming and propagating along their typical tracks in the WNP. The absolute vorticity values are greatly reduced from what would be found in a typical TC (even after accounting for the great underresolution of the TC vortex in the reanalysis) due to the fact that the ACE index sums over many storms forming in different locations throughout the basin. The negative vorticity band might perhaps have been less straightforwardly expected. The vorticity dipole remaining at week +2 , straddling the equator, persists to much longer lags, and is believed to be primarily an ENSO signal, discussed further in section $3 \mathrm{~b}$.

\section{2) OLR}

Figure 3 shows OLR, in the same format as Fig. 2 for the relative vorticity. Particularly at weeks -1 and 0 , the primary features can be described to some extent by simply repeating the description of the vorticity shown 
(a)

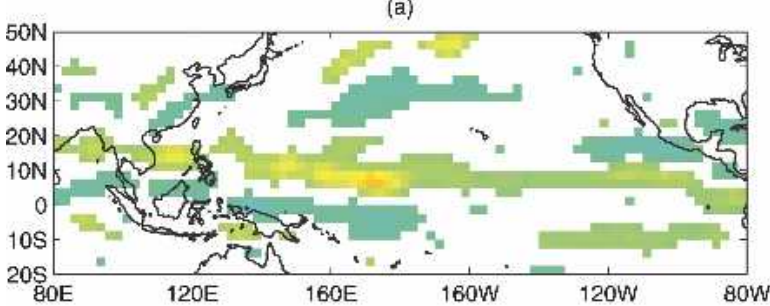

(b)

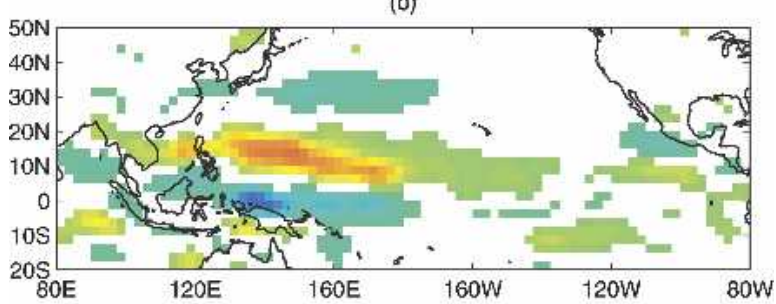

(c)



(d)

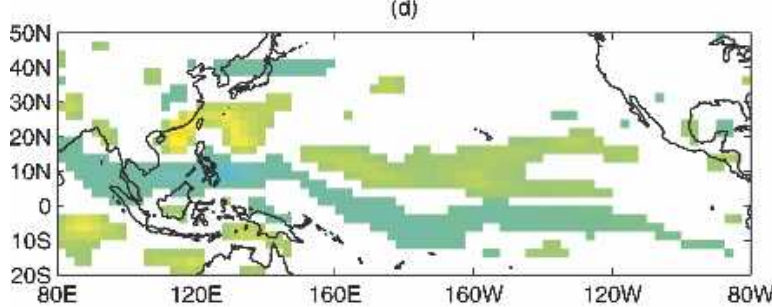

(e)
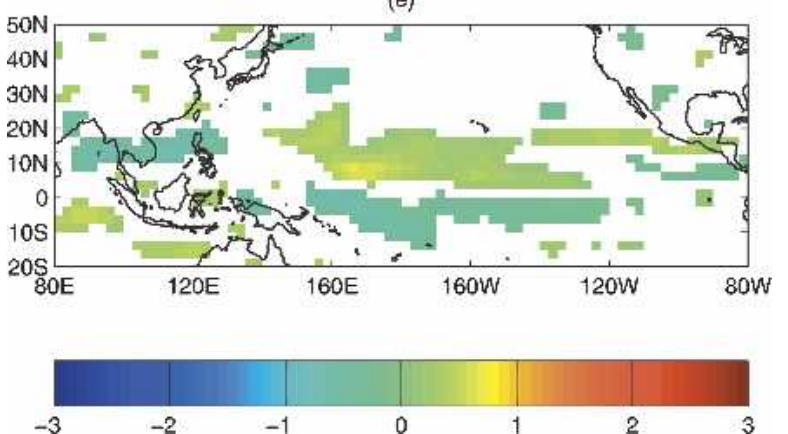

FIG. 2. Lag regression of weekly relative vorticity $\left(\mathrm{s}^{-1}\right)$ at 850 $\mathrm{hPa}$ on ACE, for weeks (a) -2 , (b) -1 , (c) 0 , (d) +1 , and (e) +2 , where positive lag means ACE leads vorticity.

in the preceding figure, substituting a negative OLR anomaly for a positive vorticity anomaly, and vice versa. At week -2 , a somewhat east-west-oriented low-OLR region is centered near the equator, and just west of the date line. This anomaly moves northwest-



(b)
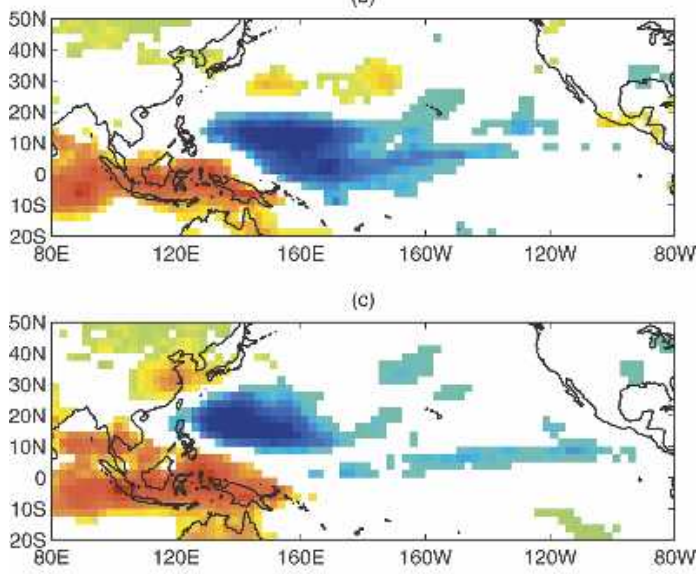

(d)



(e)
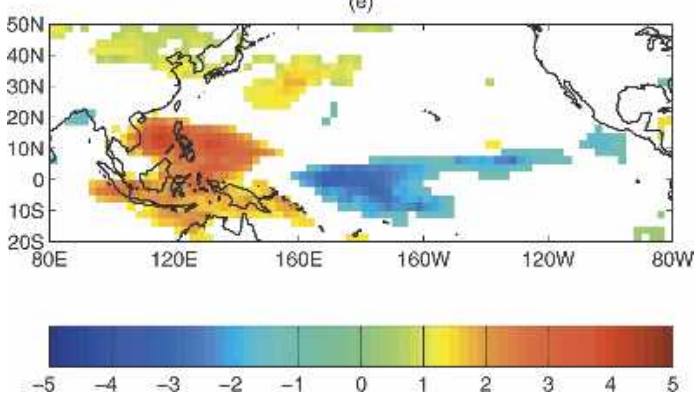

FIG. 3. Lag regression of weekly OLR $\left(\mathrm{W} \mathrm{m}^{-2}\right)$ on ACE, for weeks (a) -2 , (b) -1 , (c) 0 , (d) +1 , and (e) +2 , where positive lag means ACE leads OLR.

ward by week 0 , again following a highly blurred version of a typical TC track on weeks -1 and 0 , and dissipates by week +1 . The maximum amplitude of the negative OLR anomaly is reached on week -1 , interestingly different from the positive vorticity anomaly, which maximized at week 0 . The negative OLR anomaly is accompanied by a positive OLR anomaly to its southwest (SW) on weeks -1 and 0 , which strengthens and moves northward on weeks +1 and +2 . During 
weeks +1 and +2 the equatorial negative OLR near the date line also re-establishes itself, with a longer, narrow branch slightly north of the equator extending from around $150^{\circ} \mathrm{E}$ eastward. Given the relatively rapid time scale, it is possible that some of this eastern signal could be due to the MJO or convectively coupled Kelvin waves (Wheeler and Kiladis 1999).

\section{3) Atmospheric temperature}

Figure 4 shows atmospheric temperature at the 500$\mathrm{hPa}$ pressure level. At week -2 , we see a warm anomaly centered well south of the equator and extending poleward and eastward along the equator, and a very weak cold anomaly between Indonesia and the Philippines. At week -1 this structure persists and in addition another warm anomaly, elongated longitudinally and oriented nearly east-west, develops in the latitude range between the Philippines and Japan, extending from inland of the Asian coast to about $160^{\circ} \mathrm{E}$. At week 0 the latter anomaly, which we take to be the signal of the typical TC itself, has moved northwestward and intensified considerably. At week +1 this warm anomaly moves northward and weakens, while a cold anomaly develops to its south, roughly centered on the equator but extending well into the Southern Hemisphere. At week +2 the warm anomaly is nearly gone, while a cold anomaly, centered around $20^{\circ} \mathrm{N}$, now extends east-west from the western boundary of the domain shown to around $160^{\circ} \mathrm{E}$, with a roughly mirrorimage cold anomaly south of the equator. Some aspects of this picture are expected in that we expect warm anomalies to accompany TCs. However, the strongest warm anomalies in week 0 are centered to the north of the strongest vorticity and OLR anomalies in the preceding two figures. The cold anomaly in week +2 might perhaps also not have been straightforwardly expected, although its northern lobe may perhaps be related to the negative SST anomaly at this lag (shown below in Fig. 5).

\section{4) SST}

Figure 5 shows the lag regression of SST on ACE. The first feature that one notices in this figure is the pattern characteristic of El Niño in all five panels, with an equatorial warm anomaly in the central and eastern Pacific, and cold anomalies to the west. This tells us that not only are ENSO and ACE correlated, but ENSO is the single strongest influence on ACE; otherwise this pattern would not be so strong. In addition to the primary El Niño warm anomaly, warm anomalies spread much farther north, with a local maximum extending southwest-northeast from low latitudes near the date

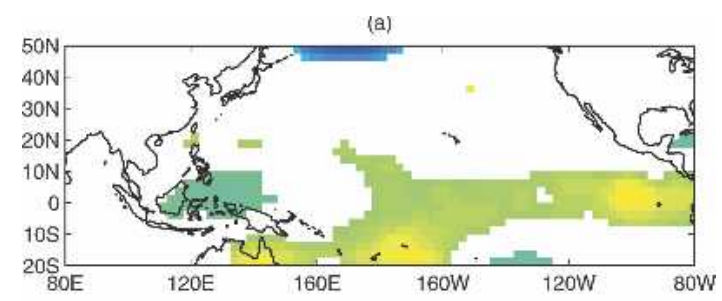

(b)



(c)

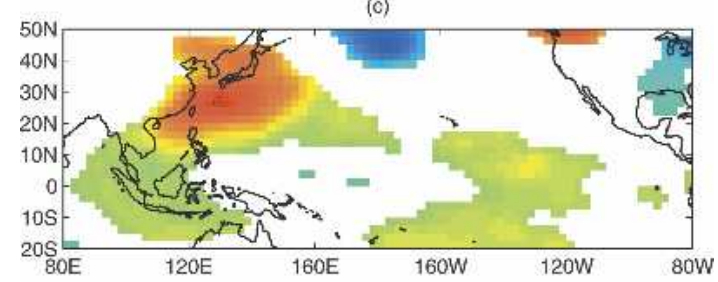

(d)
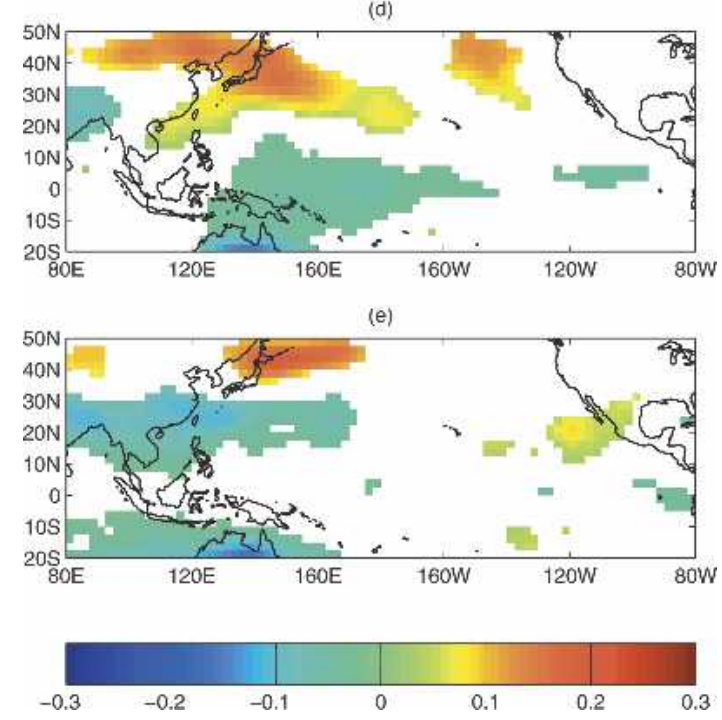

FIG. 4. Lag regression of weekly $500-\mathrm{hPa}$ temperature $(\mathrm{K})$ on ACE, for weeks (a) -2 , (b) -1 , (c) 0 , (d) +1 , and (e) +2 , where positive means ACE leads 500-hPa temperature.

line to the U.S. Pacific Northwest. Like the El Niño pattern, this anomaly persists for all five panels (and to much longer leads and lags) and thus results from long time scale correlation as opposed to the (composite) effects of individual storms.

Looking at variations from lag -2 to +2 , we see signals that we do interpret as associated with individual TCs. To bring these out, in Fig. 6 we show the same fields as in Fig. 5, but with the average of the five 
(a)

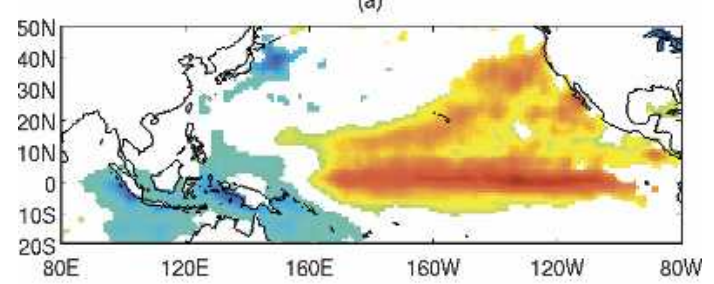

(b)



(c)

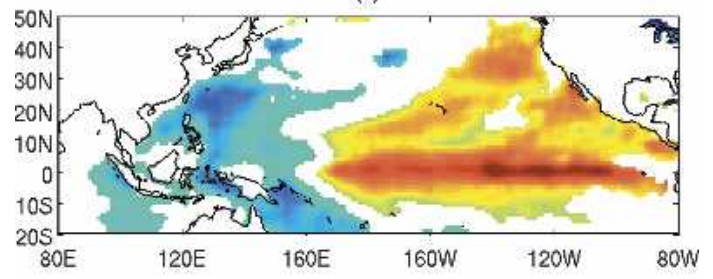

(d)

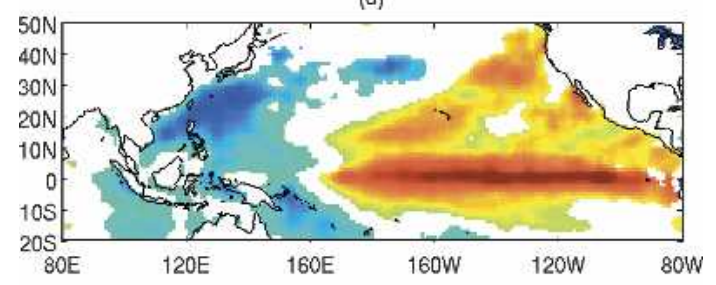

(e)
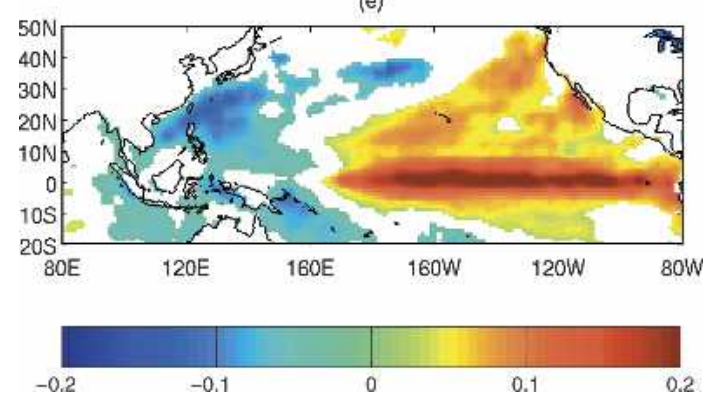

FIG. 5. Lag regression of weekly SST (K) on ACE, for weeks (a) -2 , (b) -1 , (c) 0 , (d) +1 , and (e) +2 , where positive lag means ACE leads SST.

weeks subtracted, so only changes over that period are shown. As might have been expected, a local cooling under the main region of TC activity in the western North Pacific develops as the period proceeds. Its magnitude is quite low, $\sim 0.1^{\circ} \mathrm{C}$ at lag 0 , compared to that which would be found on small spatial scales immediately under an individual TC, which can be greater than $5^{\circ} \mathrm{C}$ (Lin et al. 2003). Again this is an average over many small-scale events, each presumably having a



(b)

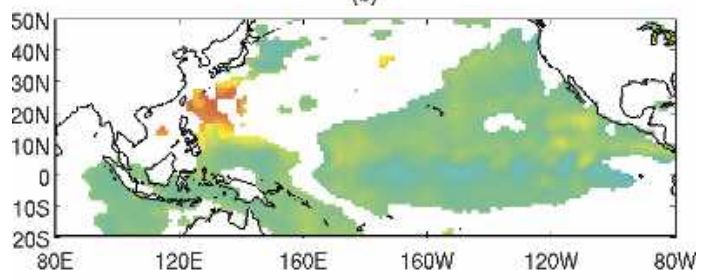

(c)



(d)

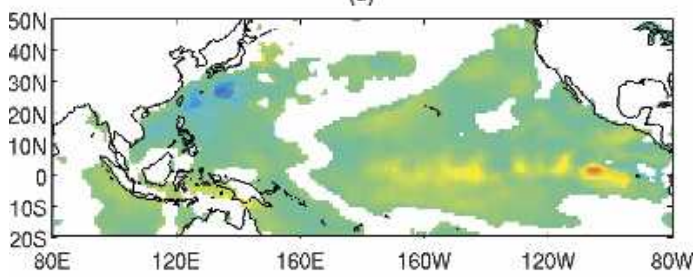

(e)


FIG. 6. Time-varying part of the field shown in Fig. 5. That is, lag regression of weekly SST $(\mathrm{K})$ on ACE, for weeks -2 to +2 is computed, and then the mean of the result over the five weeks is subtracted from each frame.

much stronger signal but at different locations; it is also possible that, given its small spatial scale, the cooling in individual events might be underestimated in the Reynolds dataset. Another time-dependent feature that is evident in the figure is the warming on the equator near and east of the date line. While the warm anomaly is persistent throughout the period (and at much longer and shorter lags), it intensifies considerably over the 
period shown. We presume that the warming is an ocean-dynamical response to the surface westerly anomalies associated with the TCs, shown below in Fig. 7.

\section{5) Surface zonal wind}

Figure 7 shows surface zonal wind. At lag -2 , the WNP contains a north-south dipole structure (consistent with positive relative vorticity centered between the two poles) that is elongated in the east-west direction. A weak positive anomaly is also located north of the negative one, vaguely mirroring the tripolar structure found in the vorticity at this time (Fig. 1). At lags -1 and 0 , the main dipole strengthens and moves northwestward, the northernmost westerly anomaly dissipates, and a new easterly anomaly develops on the equator over the Maritime Continent and Indian Ocean. At lag +1 the northern easterly anomalies have dissipated and the westerly anomalies have weakened over and just east of the Philippines (where they were strongest during the previous week), but have strengthened and now extend somewhat further east along the equator. At week +2 , the only significant anomalies remaining are the equatorial westerly anomalies near the date line, and the easterlies over the Maritime Continent and Indian Ocean. As will be shown in the following section, these anomalies at lag +2 are to a significant degree a result of the long time scale correlation between ACE and ENSO, and do not necessarily reflect the influence of the storms responsible for the anomalous ACE at lag 0 .

As the reanalysis surface winds in the Tropics are heavily dependent on the numerical model used for data assimilation, and are thus subject to some doubt, the lag regression in Fig. 7 was also computed using the European Centre for Medium-Range Weather Forecasts (ECMWF) operational analysis surface winds (ECMWF 2004). The results (not shown) were not significantly different.

\section{6) Column water vapor}

Figure 8 shows total column water vapor. At lag -2 , we have a moist anomaly roughly collocated with the negative low OLR anomaly at the same time in Fig. 3, and a dry anomaly over the Maritime Continent. This pattern strengthens and shifts northwestward from lags -1 to 0 . From lags +1 to +2 , the moist anomaly dissipates, but the dry anomaly remains, and has shifted slightly northeastward, now covering the Philippines and overlapping significantly with the primary region of TC genesis and development (which we can simply de-
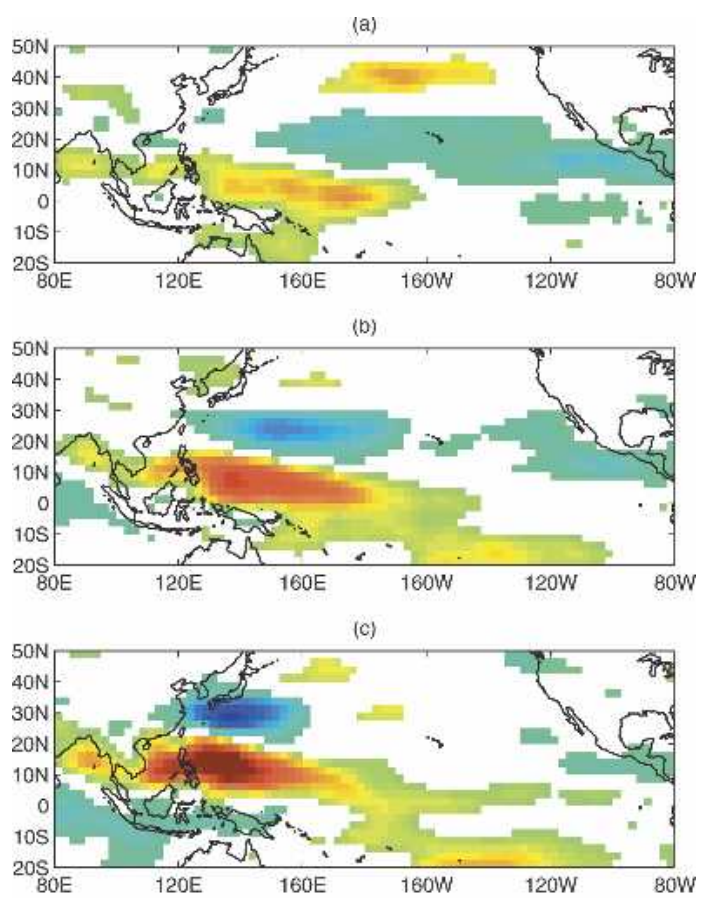

(d)
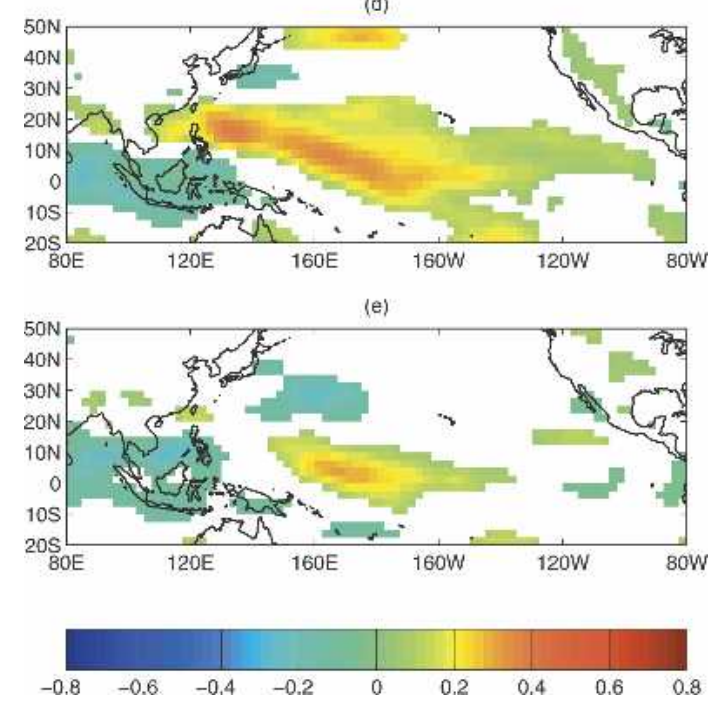

FIG. 7. Lag regression of weekly surface zonal wind $\left(\mathrm{m} \mathrm{s}^{-1}\right)$ on ACE, for weeks (a) -2 , (b) -1 , (c) 0 , (d) +1 , and (e) +2 , where positive lag means ACE leads surface zonal wind.

fine as the location of the main positive $850-\mathrm{hPa}$ vorticity anomalies, negative OLR anomalies, and positive column water vapor anomalies, at weeks -1 and 0 in Figs. 2, 3, and 8). The dry anomaly over the Maritime Continent at lag -2 is a result of the longer time scale correlation of ACE and ENSO, but the one at lag +2 is not completely so, also containing some short time scale TC influence. 

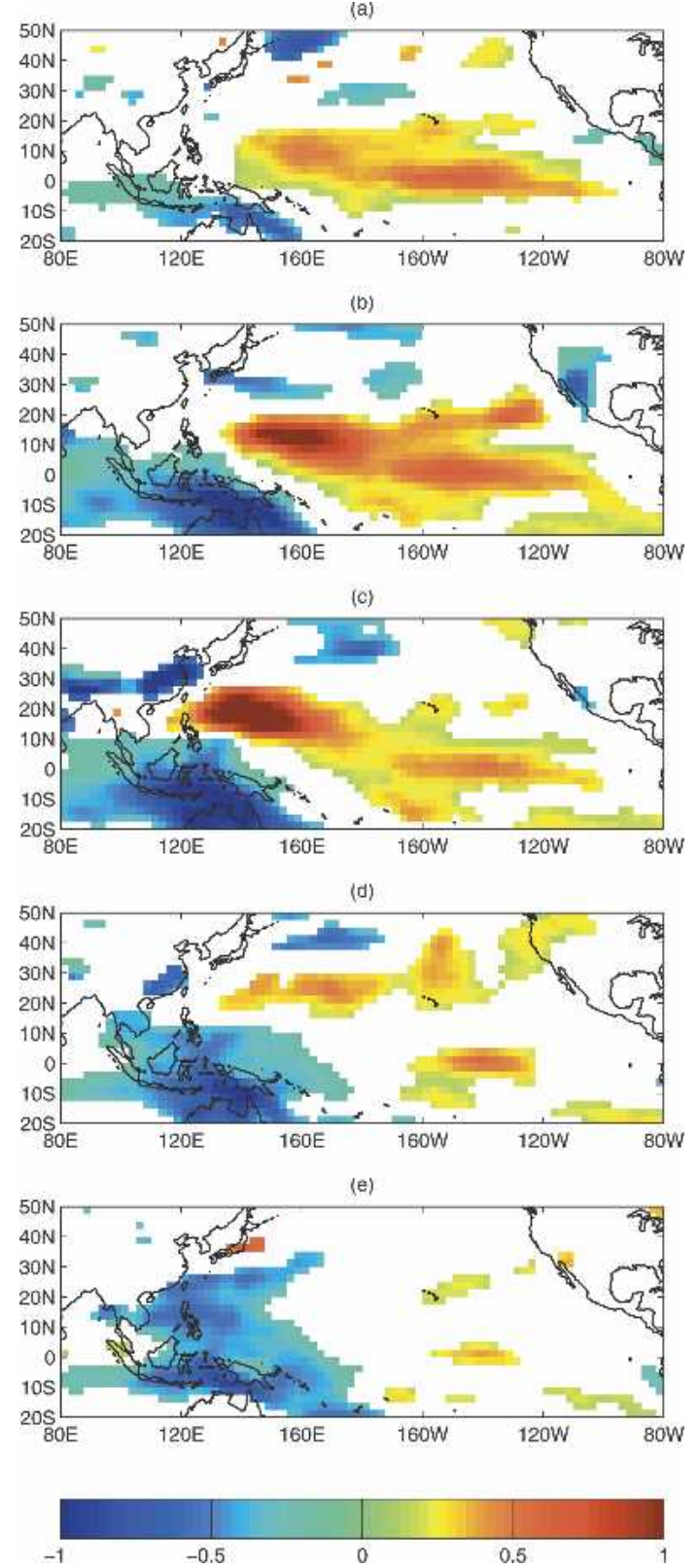

FIG. 8. Lag regression of weekly total column water vapor $(\mathrm{mm})$ on ACE, for weeks (a) -2 , (b) -1 , (c) 0 , (d) +1, and (e) +2 , where positive lag means ACE leads column water vapor.

\section{b. Signals at longer time scales}

In the preceding section, we claimed that certain signals were related to the correlations between ENSO and ACE on interannual time scales. These signals presumably reflect an influence of ENSO on ACE rather than vice versa. We contrasted these to the short time scale signals that were the focus of the previous section, and which we took to reflect the immediate influence of TCs on their environment. In this section, we illuminate

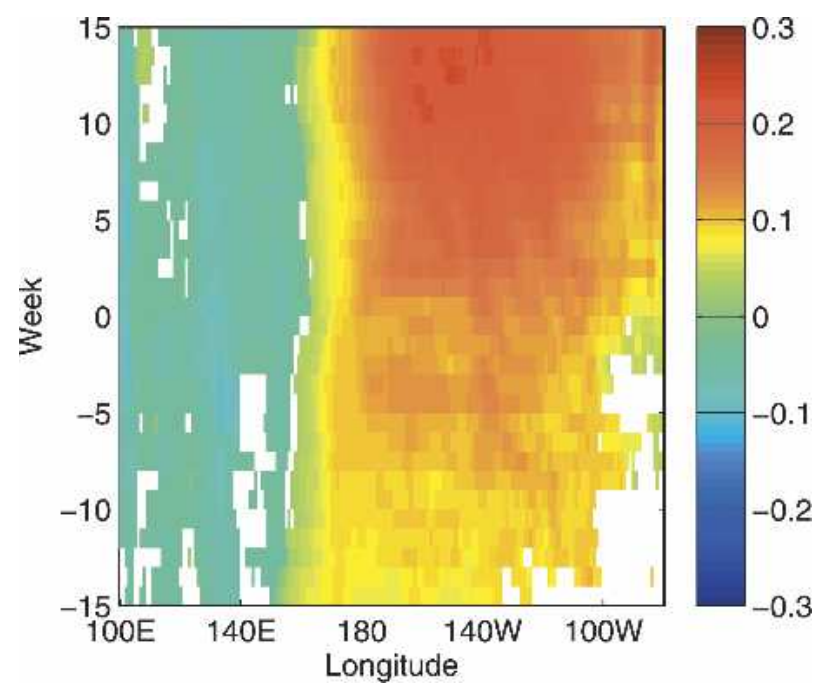

FIG. 9. Lag regression of weekly equatorial $\left(5.5^{\circ} \mathrm{S}-5.5^{\circ} \mathrm{N}\right.$ average) SST (K) on ACE, from weeks -15 to +15 , shown as a function of longitude and time, where positive lag means ACE leads SST.

the longer time scale signals by showing a couple of lag regressions over a larger range of leads and lags.

Figures 9 and 10 show time-longitude Hovmoeller plots of SST and surface zonal wind, averaged from $5.5^{\circ} \mathrm{S}-5.5^{\circ} \mathrm{N}$, lag regressed on $\mathrm{ACE}$ from lags -15 to +15 weeks. Both show increases over time. The zonal wind increases most in a $\sim 20^{\circ}$ longitude band just west of and at the date line, the SST in a broader longitude

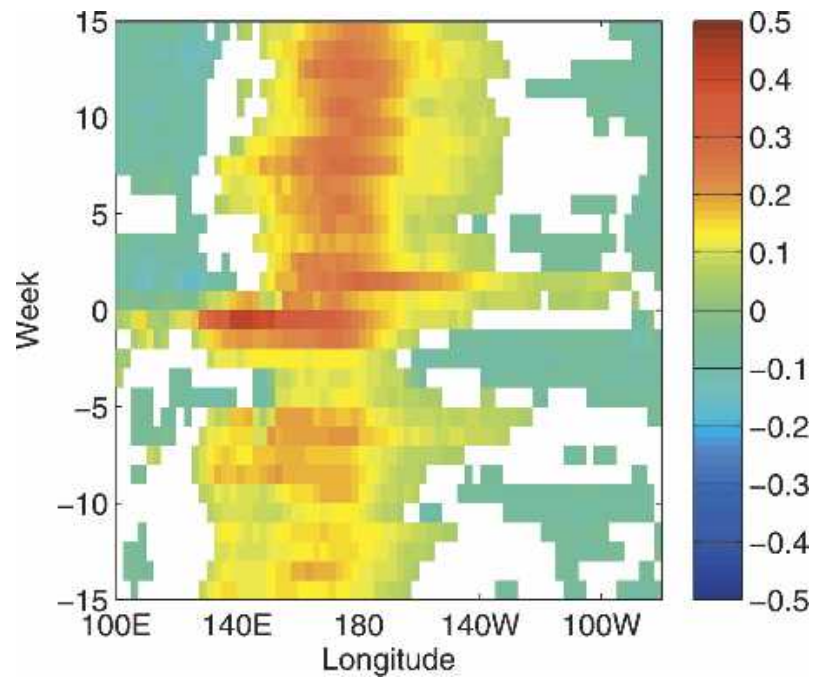

FIG. 10. Lag regression of weekly equatorial $\left(5.5^{\circ} \mathrm{S}-5.5^{\circ} \mathrm{N}\right.$ average) surface zonal wind $\left(\mathrm{m} \mathrm{s}^{-1}\right)$ on ACE, from weeks -15 to +15 , shown as a function of longitude and time, where positive lag means ACE leads zonal wind. 
band at and east of the date line. Temporally, both fields show a slow component to the increase over a long time period, but both also have relatively sharp increases at certain times, the zonal wind just before and at lag zero, the SST several weeks later. The zonal wind also has an oscillatory component on an intraseasonal time scale, particularly at negative through small positive lags.

Our interpretation of these results is as follows. The slow increasing trends in zonal wind and SST represent the development of an ENSO event. The association of $\mathrm{ACE}$ with these slow trends is probably a consequence of the correlation of ACE with ENSO in the seasonal mean (Camargo and Sobel 2005). The fact that much of the increase occurs at positive lags likely results simply from the fact that ENSO events tend to peak in northern winter while TC activity in the western North Pacific (and thus the ACE signal) peaks in northern summer and fall. On the other hand, the sharpness of the increases near lag 0 for the zonal wind and around lag +5 for the SST presumably indicates some direct influence exerted by the TCs on these fields. We might speculate that the delay of the SST increase relative to the zonal wind increase represents the time for the oceanic signal to be transmitted eastward, to a region of smaller thermocline depth (and thus greater sensitivity of SST to ocean dynamics) presumably by oceanic Kelvin waves. The time lag of several weeks and the displacement of several thousand kilometers eastward of the SST warming relative to the surface westerly anomalies are roughly consistent with the $2.3 \mathrm{~m} \mathrm{~s}^{-1}$ phase speed estimated for such waves by Hendon et al. (1998).

The intraseasonal oscillatory component in the zonal wind in Fig. 9 presumably results from the relationship of ACE to the MJO. To examine this further, we used the MJO index defined by Wheeler and Hendon (2004), binned weekly to match our weekly ACE time series. Their index RMM2 represents the state of the MJO in the western Pacific. This index is correlated weakly (0.14), but significantly ( $>95 \%$ ) with ACE, as might be expected given the known relationship between the MJO and tropical cyclones (e.g., Liebmann et al. 1994). For comparison, the instantaneous correlation between weekly anomalous ACE and the weekly Niño-3.4 index is 0.13 , and the level of significance is approximately the same as for the MJO-ACE correlation. The maximum correlation between anomalous ACE and Niño-3.4 (at week +13, ACE leads Niño-3.4 by 13 weeks) is 0.22 . Much larger correlations between ACE and Niño-3.4 are obtained if the time series are averaged over longer periods; for example, total ACE per year and Niño-3.4 averaged from July to October have a correlation of 0.70 ; see Camargo and Sobel (2005) for more details.

\section{Discussion}

\section{a. Effects of TC on future TC genesis}

The SST reduction that is found to be induced by a period of enhanced ACE is expected. The SST reduction under an individual cyclone has been studied for its influence on later cyclones that cross its path (e.g., Brand 1971) or on the same one that itself induces the cooling (e.g., Schade and Emanuel 1999; Emanuel 1999). Although the SST reduction is initially small in spatial scale, over time adjustment mechanisms in the ocean and atmosphere should spread it to larger scales. This will reduce (by a smaller amount) the potential of a larger region for the development of additional TCs. Some of the other effects found above at lags +1 and +2 , in particular the drying and OLR increase found in the main region of TC activity, may also indicate similarly reduced genesis potential. These atmospheric effects may be induced by the SST reduction, or may be induced in the atmosphere directly by the TCs.

In the western north Pacific, TCs often form in pairs or even threes, with a typical spacing and dynamical signature indicative of Rossby wave dispersion (Davidson and Hendon 1989; Carr and Elsberry 1995; Holland 1995; Briegel and Frank 1997; Ritchie and Holland 1999; Sobel and Bretherton 1999; Li et al. 2003). This tends to indicate that one has positively influenced the genesis of the next, a positive feedback. The present results provide a contrast to this, since they seem to indicate that TCs also influence their environment in such a way as to negatively influence the genesis of future storms. Quantifying the importance, absolute and relative, of these effects is an open challenge.

\section{b. The TC effects on ENSO}

The suggestion of a connection of TCs to ENSO dynamics is perhaps the more provocative aspect of the results shown above. From these statistical results alone it is impossible to extract a definitive proof of this connection, but we can sketch out the hypothesis that the results suggest to us, and point out some of the ways in which the data support this hypothesis, as well as some of the weaknesses in the argument.

The hypothesis, in the strongest form we can make it, is that TCs are active participants in ENSO dynamics. In an El Niño year, stronger and longer-lived TCs occur during the northern summer and fall before the El Niño peak. These TCs then produce equatorial westerly anomalies that help to strengthen the incipient El Niño event by amplifying the warming of the upper ocean in 
the eastern and central equatorial Pacific. This is essentially the standard Bjerknes hypothesis (Bjerknes 1969) except that TCs are postulated to participate actively in the process, in addition to the other mechanisms by which eastern and central Pacific equatorial warm SST anomalies generate surface westerly anomalies (Walker circulation, MJO, etc.). Related arguments have been made recently, to the effect that ENSO may modulate westerly wind bursts in such a way as to induce a positive feedback on itself, and that TCs may play some role in this (Yu and Rienecker 1998; Yu et al. 2003; Eisenman et al. 2005).

The first part of this hypothesis, that TCs are stronger and longer-lived in the seasons during which El Niño events develop, is reasonably well established, having been documented in various ways by several previous studies (e.g., Pudov and Petrichenko 1998, 2001; Wang and Chan 2002; Chia and Ropelewski 2002; Chan and Liu 2004; Camargo and Sobel 2005). Since the intrinsic time scale of ENSO is much longer than that of a TC, we must assume that the simultaneous correlation results from an influence of ENSO on TCs, rather than the other way around. The mechanism of this influence, in our view, is not conclusively established.

The second part of the hypothesis, that TCs influence ENSO, is likely to be more controversial, though it has been made before (Keen 1982; Gao et al. 1988). The key questions are whether TCs really induce surface equatorial westerlies (or at least westerly anomalies), and if so, whether those westerlies have an effect that is large and long-lasting enough to contribute materially to ENSO.

Simple deformation radius arguments suggest that we can expect TCs forming sufficiently near the equator to generate equatorial westerly anomalies, and to project on atmospheric equatorial Kelvin waves. The eastward propagation of the westerly anomalies shown in Fig. 7 suggests that the latter occurs.

Similarly, it might be argued that any statistical relationship that exists between ACE and equatorial westerlies is coincidental, and that the more fundamental relationship is between the MJO and ENSO (e.g., Lau and Chan 1986, 1988; Moore and Kleeman 1999; Bergman et al. 2001), though there is no consensus on the nature or degree of the influence of the MJO on ENSO (Zhang et al. 2001). Equatorial westerlies are associated with the MJO, and these westerlies are generally associated with cyclonic vorticity just poleward of the equator, creating a more favorable environment for cyclogenesis there (e.g., Love 1985a,b; see also Lander 1990). The large-scale convergence associated with the MJO westerlies could also lead to genesis via wave accumulation (e.g., Sobel and Maloney 2000). These fac- tors would lead to an association between equatorial westerlies and TCs even if the cyclones were to have no role in producing the westerlies (e.g., Love 1985a,b; see also Lander 1990), but at the same time this does not prove that the cyclones play no role in enhancing the westerlies.

We cannot resolve this question here. We just point out that the westerly anomaly signal shows up in regressions on an index based on TCs alone (i.e., ACE), and suggest that this result may indicate a role for TCs, modulated by the MJO or otherwise. Some observational studies of westerly wind bursts have made a strong association between those bursts and TCs (e.g., Harrison and Giese 1991; Kindle and Phoebus 1995), while others have not mentioned them at all (e.g., Kiladis et al. 1994; Harrison and Vecchi 1997; McPhaden 2004), though some of the latter mention cyclonic anomalies or similar, without indicating whether those correspond to known TCs in the data record. Despite this apparent lack of a consensus on the role of TCs, we are not aware of much direct written debate on the subject, with a few exceptions (e.g., Lander 1990).

\section{Conclusions}

We have computed lag regressions of a number of large-scale climate variables with ACE, an index of TC activity, in the western North Pacific. Several different sorts of signals are evident in the results. We see long time scale signals representing first and foremost the influence of ENSO on ACE, and to a lesser degree the influence of the MJO on ACE. On the time scale of a few weeks, we see signals indicating the composite TC itself, which appears as a diffuse, weak blob of high vorticity, low OLR, high column water vapor, etc. On this time scale we also see immediate effects of the TCs on their environment.

The TCs induce an SST reduction in the primary region of TC activity. They also induce cooling, drying, and reduction of OLR in the atmosphere over a region that partly overlaps with the primary region of TC activity, but is centered somewhat to the south and west. These atmospheric signals may be byproducts of the SST cooling, or may be induced directly by the TCs via the atmosphere. These effects (on both the atmosphere and ocean) are of the right sign to represent negative feedbacks on the environment for future cyclogenesis.

The TCs also induce equatorial surface westerly anomalies near the date line, and an associated SST increase in the central and eastern Pacific. These signals are of the right sign to contribute to the enhancement of a developing El Niño. Since peak-season ACE tends to be higher (stronger, longer-lived TCs) during the years when an El Niño is building, this suggests the 
possibility of a two-way positive feedback between ENSO and TC activity.

Acknowledgments. We thank Anthony Barnston, Mark Cane, and Stephen Zebiak for discussions, and the reviewers for helpful comments. AHS acknowledges support for this work from the David and Lucile Packard Foundation. This work was supported by the IRI and a cooperative agreement from the National Oceanic and Atmospheric Administration (NOAA).

\section{REFERENCES}

Bell, G. D., and Coauthors, 2000: Climate assessment for 1999. Bull. Amer. Meteor. Soc., 81, S1-S50.

Bergman, J. W., H. H. Hendon, and K. M. Weickmann, 2001: Intraseasonal air-sea interactions at the onset of El Niño. $J$. Climate, 14, 1702-1719.

Bjerknes, J., 1969: Atmospheric teleconnections from the equatorial Pacific. Mon. Wea. Rev., 97, 163-172.

Brand, S., 1971: The effects on a tropical cyclone of cooler surface waters due to upwelling and mixing produced by a prior tropical cyclone. J. Appl. Meteor., 10, 865-874.

Briegel, L. M., and W. M. Frank, 1997: Large-scale influences on tropical cyclogenesis in the western North Pacific. Mon. Wea. Rev., 125, 1397-1413.

Camargo, S. J., and A. H. Sobel, 2004: Western North Pacific tropical cyclone intensity and ENSO. IRI Tech. Rep. 04-03, International Research Institute for Climate Prediction, Palisades, NY, $25 \mathrm{pp}$.

— tensity and ENSO. J. Climate, 18, 2996-3006.

Carr, L. E., III, and R. L. Elsberry, 1995: Monsoonal interactions leading to sudden tropical cyclone track changes. Mon. Wea. Rev., 123, 265-289.

Chan, J. C. L., and K. S. Liu, 2004: Global warming and western North Pacific typhoon activity from an observational perspective. J. Climate, 17, 4590-4602.

Chia, H. H., and C. F. Ropelewski, 2002: The interannual variability in the genesis location of tropical cyclones in the northwest Pacific. J. Climate, 15, 2934-2944.

Davidson, N. E., and H. H. Hendon, 1989: Downstream development in the Southern Hemisphere monsoon during FGGE/ WMONEX. Mon. Wea. Rev., 117, 1458-1470.

ECMWF, cited 2004: ECMWF 40 Years Re-Analysis, daily fields. [Available online at http://data.ecmwf.int/data/d/era40_ daily/.]

Eisenman, I., L. Yu, and E. Tziperman, 2005: Westerly wind bursts: ENSO's tail rather than the dog's? J. Climate, in press.

Emanuel, K. A., 1999: Thermodynamic control of hurricane intensity. Nature, 401, 665-669.

— 2001: Contribution of tropical cyclones to meridional heat transport by the oceans. J. Geophys. Res., 106, 14 771-14 781.

Ferreira, R. N., W. H. Schubert, and J. Hack, 1996: Dynamical aspects of twin tropical cyclones associated with the MaddenJulian oscillation. J. Atmos. Sci., 53, 929-945.

Gao, S., J. Wang, and Y. Ding, 1988: The triggering effect of near-equatorial cyclones on El Niño. Adv. Atmos. Sci., 5, $87-95$.

Gray, W. M., 1979: Hurricanes: Their formation, structure and likely role in the tropical circulation. Meteorology over the
Tropical Oceans, D. B. Shaw, Ed., Royal Meteorological Society, 155-218.

Harrison, D. E., and B. S. Giese, 1991: Episodes of surface westerly winds as observed from islands in the western tropical Pacific. J. Geophys. Res., 96, 3221-3237.

_ and G. A. Vecchi, 1997: Westerly wind events in the tropical Pacific, 1986-95. J. Climate, 10, 3131-3156.

Hendon, H. H., B. Liebmann, and J. D. Glick, 1998: Oceanic Kelvin waves and the Madden-Julian oscillation. J. Atmos. Sci., 55, 88-101.

Holland, G. J., 1995: Scale interaction in the western North Pacific monsoon. Meteor. Atmos. Phys., 56, 57-79.

JTWC, cited 2004: Joint Typhoon Warning Center best track dataset. [Available online at https://metoc.npmoc.navy.mil/ jtwc/best_tracks/.]

Kalnay, E., and Coauthors, 1996: The NCEP/NCAR 40-Year Reanalysis Project. Bull. Amer. Meteor. Soc., 77, 437-471.

Keen, R. A., 1982: The role of cross-equatorial tropical cyclone pairs in the Southern Oscillation. Mon. Wea. Rev., 110, 14051416.

Kiladis, G. N., G. A. Meehl, and K. M. Weickmann, 1994: Largescale circulation associated with westerly wind bursts and deep convection over the western equatorial Pacific. J. Geophys. Res., 99, 18 527-18 544.

Kindle, J. C., and P. A. Phoebus, 1995: The ocean response to operational westerly wind bursts during the 1991-1992 El Niño. J. Geophys. Res., 100, 4893-4920.

Lander, M. A., 1990: Evolution of the cloud pattern during the formation of tropical cyclone twins symmetrical with respect to the equator. Mon. Wea. Rev., 118, 1194-1202.

Lau, K.-M., and P. H. Chan, 1986: The 40-50 day oscillation and the El Niño-Southern Oscillation: A new perspective. Bull. Amer. Meteor. Soc., 67, 533-534.

— and - 1988: Intraseasonal and interannual variations of tropical convection: A possible link between the $40-50$ day oscillation and ENSO? J. Atmos. Sci., 45, 506-521.

Li, T., B. Fu, X. Ge, B. Wang, and M. Peng, 2003: Satellite data analysis and numerical simulation of tropical cyclone formulation. Geophys. Res. Lett., 30, 2122, doi:10.1029/ 2003GL018556.

Liebmann, B., and C. A. Smith, 1996: Description of a complete (interpolated) outgoing longwave radiation dataset. Bull. Amer. Meteor. Soc., 77, 1275-1277.

- H. H. Hendon, and J. D. Glick, 1994: The relationship between tropical cyclones of the western Pacific and Indian Oceans and the Madden-Julian oscillation. J. Meteor. Soc. Japan, 72, 401-411.

Lin, I.-I., W. T. Liu, C.-C. Wu, J. C. H. Chiang, and C.-H. Sui, 2003: Satellite observations of modulation of surface winds by typhoon-induced upper ocean cooling. Geophys. Res. Lett., 30, 1131, doi:10.1029/2002GL015674.

Livezey, R. E., and W. Y. Chen, 1983: Statistical field significance and its determination by Monte Carlo techniques. Mon. Wea. Rev., 111, 46-59.

Love, G., 1985a: Cross-equatorial influence of winter hemisphere subtropical cold surges. Mon. Wea. Rev., 113, 1487-1498.

_ 1985b: Cross-equatorial interactions during tropical cyclogenesis. Mon. Wea. Rev., 113, 1499-1509.

Madden, R. A., and P. R. Julian, 1994: Observations of the 4050-day tropical oscillation-A review. Mon. Wea. Rev., 122, 814-837.

McPhaden, M. J., 2004: Evolution of the 2002/03 El Niño. Bull. Amer. Meteor. Soc., 85, 677-695. 
Moore, A. M., and R. Kleeman, 1999: Stochastic forcing of ENSO by the intraseasonal oscillation. J. Climate, 12, 1199-1220.

Pudov, V. D., and S. A. Petrichenko, 1998: Relationship between the evolution of tropical cyclones in the northwestern Pacific and El Niño. Oceanology, 38, 447-452.

_, and _ 2001: 1997-1998 El Niño and tropical cyclone genesis in the northwestern Pacific. Izv. Atmos. Oceanic Phys., 37, 576-583.

Reynolds, R. W., N. A. Rayner, T. M. Smith, D. C. Stokes, and W. Wang, 2002: An improved in situ and satellite SST analysis for climate. J. Climate, 15, 1609-1625.

Ritchie, E. A., and G. J. Holland, 1999: Large-scale patterns associated with tropical cyclogenesis in the western Pacific. Mon. Wea. Rev., 127, 2027-2043.

Schade, L., and K. A. Emanuel, 1999: The ocean's effect on the intensity of tropical cyclones: Results from a simple coupled atmosphere-ocean model. J. Atmos. Sci., 56, 642-651.

Sobel, A. H., and C. S. Bretherton, 1999: Development of synoptic-scale disturbances over the summertime tropical northwest Pacific. J. Atmos. Sci., 56, 3106-3127.

- and E. D. Maloney, 2000: Effect of ENSO and the MJO on western North Pacific tropical cyclones. Geophys. Res. Lett., 27, 1739-1742.

Wang, B., and J. C. L. Chan, 2002: How strong ENSO events affect tropical storm activity over the western North Pacific. J. Climate, 15, 1643-1658.

Wheeler, M. C., and G. N. Kiladis, 1999: Convectively coupled equatorial waves: Analysis of clouds and temperature in the frequency domain. J. Atmos. Sci., 56, 374-399.

— and H. H. Hendon, 2004: An all-season real-time multivariate MJO index: Development of an index for monitoring and prediction. Mon. Wea. Rev., 132, 1917-1932.

Yu, L., and M. M. Rienecker, 1998: Evidence of an extratropical atmospheric influence during the onset of the 1997-98 El Niño. Geophys. Res. Lett., 25, 3537-3540.

- R. A. Weller, and W. T. Liu, 2003: Case analysis of a role of ENSO in regulating the generation of westerly wind bursts in the western equatorial Pacific. J. Geophys. Res., 108, 3128, doi:10.1029/2002JC001498.

Zhang, C., H. H. Hendon, W. S. Kessler, and A. J. Rosati, 2001: A workshop on the MJO and ENSO. Bull. Amer. Meteor. Soc., 82, 971-976. 